\title{
Garlic-derived S-allylmercaptocysteine is a hepato-protective agent in non-alcoholic fatty liver disease in vivo animal model
}

\author{
Jia Xiao $\cdot$ Yick Pang Ching $\cdot$ Emily C. Liong • \\ Amin A. Nanji • Man Lung Fung • George L. Tipoe
}

Received: 29 September 2011 / Accepted: 9 January 2012/Published online: 26 January 2012

(C) The Author(s) 2012. This article is published with open access at Springerlink.com

\begin{abstract}
Purpose To investigate the hepato-protective properties and underlying mechanisms of SAMC in a non-alcoholic fatty liver disease (NAFLD) rat model.

Methods Female rats were fed with a diet comprising highly unsaturated fat diet (30\% fish oil) for 8 weeks to develop NAFLD with or without an intraperitoneal injection of $200 \mathrm{mg} / \mathrm{kg}$ SAMC three times per week. After euthanasia, blood and liver samples of rats were collected for histological and biochemical analyses.

Results Co-treatment of SAMC attenuated NAFLDinduced liver injury, fat accumulation, collagen formation and free fatty acids (FFAs). At the molecular level, SAMC decreased the lipogenesis marker and restored the lipolysis marker. SAMC also reduced the expression levels of profibrogenic factors and diminished liver oxidative stress partly through the inhibition in the activity of cytochrome
\end{abstract}

Jia Xiao and Yick Pang Ching These authors contributed equally.

Electronic supplementary material The online version of this article (doi:10.1007/s00394-012-0301-0) contains supplementary material, which is available to authorized users.

J. Xiao · Y. P. Ching · E. C. Liong · G. L. Tipoe $(\bowtie)$ Department of Anatomy, Li Ka Shing Faculty of Medicine, The University of Hong Kong, L1-41, Laboratory Block, 21 Sassoon Road, Pokfulam, Hong Kong, SAR e-mail: tgeorge@hkucc.hku.hk

\section{A. A. Nanji}

Department of Pathology and Laboratory Medicine, Faculty of Medicine, Dalhousie University, Halifax, NS, Canada

M. L. Fung

Department of Physiology, Li Ka Shing Faculty of Medicine,

The University of Hong Kong, Pokfulam, Hong Kong
P450 2E1-dependent pathway. NAFLD-induced inflammation was also partially mitigated by SAMC treatment via reduction in the pro-inflammatory mediators, chemokines and suppressor of cytokine signaling. The protective effect of SAMC is also shown partly through the restoration of altered phosphorylation status of FFAs-dependent MAP kinase pathways and diminished in the nuclear transcription factors (NF- $\kappa \mathrm{B}$ and AP-1) activity during NAFLD development.

Conclusions SAMC is a novel hepato-protective agent against NAFLD caused by abnormal liver functions. Garlic or garlic derivatives could be considered as a potent food supplement in the prevention of fatty liver disease.

Keywords S-allylmercaptocysteine - NAFLD · Fibrosis · Oxidative stress $\cdot$ Inflammation

\section{Introduction}

Non-alcoholic fatty liver disease (NAFLD) is one of the forms of chronic liver diseases characterized by hepatic fibrosis, oxidative stress and inflammation. According to the histological classifications in clinical diagnosis, the so-called NAFLD ranges from fat accumulation in the hepatocytes without obvious fibrosis or inflammation to severe hepatosteatosis that may progress to cirrhosis and hepatocellular carcinoma [1]. It is an emerging hepatic disease with an estimated prevalence of $20-40 \%$ in Western countries [2]. The molecular mechanism for the initiation and progression of NAFLD is summarized by a "multi-hit" theory, where imbalanced lipid metabolism and insulin resistance is considered as the first hit to the liver. When insulin resistance occurs, liver becomes more vulnerable to hyperinsulinemia-induced "multi-hit" events 
involving the release of reactive oxygen species (ROS), pro-fibrogenic factors and pro-inflammatory mediators from impaired organelles. Subsequently, activated hepatic stellate cells induce excessive accumulation of extracellular matrix proteins, such as collagen, to cause fibrosis with concomitant necroinflammation and cell death [3, 4].

S-allylmercaptocysteine (SAMC) is a water-soluble sulfur compound present in aged garlic extract. Previous studies have shown that SAMC is effective in inhibiting cell growth and promoting apoptosis in several cancer cell lines [5-7]. Moreover, SAMC is also shown to play antioxidative and anti-nitrosative stress roles both in vitro and in vivo [8]. The hepato-protective effect of SAMC is exhibited in an acetaminophen-induced liver injury model and a carbon tetrachloride-induced acute injury model where SAMC inhibits the activity of cytochrome P450 2E1 (CYP2E1) and reduces oxidative stress released by chemical intoxication [9-11]. However, the protective effects and underlying mechanisms of SAMC in NAFLD remain unknown. In this study, we demonstrated that administration of SAMC in a high-fat diet voluntarily and orally fed rat model effectively attenuated NAFLD-induced hepatic injury, fibrosis, oxidative stress and inflammation partly through free fatty acids (FFAs)-dependent pathways and nuclear transcription factors.

\section{Materials and methods}

\section{Reagents}

SAMC pure powder was kindly given by Dr. Patrick M. T. Ling (Queensland University of Technology, Australia) and originally from Wakunaga Co. Ltd (Osaka, Japan). The purity of the SAMC powder is more than $95 \%$ by HPLC analysis. It does not contain any other garlic compound such as SAC or allicin. The powder was dissolved in phosphate-buffered saline containing $10 \%$ L-dextrose and $1 \%$ gum Arabic (w/v) at $\mathrm{pH}$ 4.5. Murine antinitrotyrosine monoclonal antibody was bought from Zymed (San Francisco, CA, USA). Rabbit anti-CYP2E1 polyclonal antibody was purchased from Millipore (Billerica, MA, USA). Antibody against phosphorylated ERK1/2 at Tyr204 (p-ERK) was bought from Santa Cruz Biotechnology (Santa Cruz, CA, USA). Antibody of total c-Jun was obtained from BD Biosciences (San Jose, CA, USA). Antibodies of SOCS3, phosphorylated c-Jun at Ser63 (p-cJun), phosphorylated p38 MAPK at Thr180/Tyr182 (p-MAPK), total p38 MAPK, phosphorylated $\mathrm{I} \kappa \mathrm{B} \alpha$ at $\operatorname{Ser} 32(\mathrm{p}-\mathrm{I} \kappa \mathrm{B} \alpha$ ), total $\mathrm{I} \kappa \mathrm{B} \alpha$, phosphorylated MEK1/2 at Ser217/221 (p-MEK), total MEK1/2, total ERK1/2, phosphorylated JNK at Thr183/Tyr185 (p-JNK), and total JNK were purchased from Cell Signaling (Danvers, MA, USA).
Animal experiments

Eight-week healthy female SD rats with body weight ranging from 180 to $200 \mathrm{~g}$ were purchased from the Laboratory Animal Unit (LAU), The University of Hong Kong. Rats were kept under standard conditions for 3 days before the start of the experiment with free access to animal chow and tap water. The animals were divided into four groups ( $n=7$ per group) namely: (1) control group; (2) NAFLD group; (3) SAMC treatment only group $(200 \mathrm{mg} / \mathrm{kg}$ in solvent; intraperitoneal injection; three times per week); and (4) NAFLD and SAMC co-treatment group. The development of NAFLD in rats, including the recipe and preparation protocols of diet, was performed based on our previously described voluntary oral feeding NAFLD animal model $[12,13]$. Instead of oral administration or in a dietary form, SAMC was intraperitoneally injected to avoid possible degradation prior to absorption through the gastrointestinal tract (GIT). The diet consists of $9.3 \mathrm{~g}$ AIN93MX (Dyets incorporation, Bethlehem, PA), $2.6 \mathrm{~g}$ AIN93VX (Dyets), $0.5 \mathrm{~g}$ choline bitatrate (Dyets), $1.1 \mathrm{~g}$ DL-methione (Bio-serv, Frenchtown, NJ), $57.5 \mathrm{~g}$ lactalbulmine hydrolysate (Bio-serv), $117.5 \mathrm{~g}$ dextrose (Dyets), $36.6 \mathrm{ml}$ fish oil (Sigma) and $4.5 \mathrm{~g}$ suspending agent $\mathrm{K}$ (Bio-serv) in per 1,000 ml volume. Regular chow for rat (PicoLab ${ }^{\circledR}$ Rodent Diet 20) was purchased from LabDiet (LabDiet, Brentwood, MO, USA). The calories of regular chow were provided by $25 \%$ from protein, $13 \%$ from fat and $62 \%$ from carbohydrates, while the calories of high-fat diet were provided by $35 \%$ from protein, $30 \%$ from fat and $35 \%$ from carbohydrates. The optimum dosage of SAMC was previously shown to be effective in protecting the liver from hepatic oxidative stress in mice [14]. After 8 weeks, the rats were euthanized by an overdose of anesthesia (intraperitoneal injection of $150 \mathrm{mg} / \mathrm{kg}$ pentobarbitone sodium) according to the protocols approved by the Committee of Animal Use for Research and Teaching at The University of Hong Kong. The Laboratory Animal Unit of the University of Hong Kong is fully accredited by the Association for Assessment and Accreditation of Laboratory Animal Care International (AAALAC international). Blood and liver samples were collected for further analysis.

Processing of tissue and blood samples

Serum was collected by centrifugation of whole blood sample at $1,000 \times g$ for $10 \mathrm{~min}$ at $4{ }^{\circ} \mathrm{C}$ and stored at $-80{ }^{\circ} \mathrm{C}$. Liver tissue samples were fixed in $10 \%$ phosphate-buffered formalin, processed for histology and embedded in paraffin blocks. Five-micrometer tissue sections were cut and stained with hematoxylin and eosin (H\&E) or Sirius Red for histological analysis under LEICA 
Qwin Image Analyser (Leica Microsystems Ltd., Milton Keynes, UK). The percentage area of the total amount of collagen (7 sections for each group) was quantified by the sum areas of Sirius Red positive staining divided by the reference field multiplied by 100 . The severity of NAFLD of each group was assessed by using the NAFLD activity scoring (NAS) system as previously described [15]. The mean NAS score was calculated for each experimental group.

Serum alanine aminotransferase (ALT) assay

To evaluate the hepatic injury at the enzymatic level, serum ALT level was measured by using ALT (SGPT) reagent set (Teco diagnostics, Anaheim, CA, USA) according to manufacturer's instructions.

Free fatty acids (FFAs) assay

To study the effect of SAMC on lipid metabolism, serum FFAs level of each rat was measured by using Cayman free fatty acids assay kit (Cayman chemical, Ann Arbor, MI, USA), and the final results were expressed as $\mu \mathrm{M}$ in the serum.

Measurement of malondialdehyde (MDA) level

To investigate the possible effects of SAMC on hepatic lipid peroxidation, levels of the end product of lipid peroxidation (MDA) in all liver tissue samples were determined by using a Bioxytech LPO-586 ${ }^{\mathrm{TM}}$ kit (Oxis Research, Portland, OR, USA). The reaction product was measured spectrophotometrically at $586 \mathrm{~nm}$. Standard curves were constructed using 1,1,3,3-tetraethoxypropane as a standard. The MDA levels were normalized with corresponding protein amounts determined by a Bio-Rad Protein Assay Kit (Bio-Rad, Hercules, CA, USA) and expressed as percentage against the control level.

RNA extraction and reverse transcription-quantitative polymerase chain reaction

Total RNA of each rat was extracted from the liver sample by using illustra ${ }^{\mathrm{TM}}$ RNAspin mini kit (GE healthcare, UK). The preparation of the first-strand cDNA was conducted following the instruction of the SuperScript ${ }^{\mathrm{TM}}$ First-Strand Synthesis System (Invitrogen, Calsbad, CA, USA).

The mRNA expression levels of sterol regulatory element binding protein-1c (SREBP1c), adiponectin, tumor necrosis factor-alpha (TNF- $\alpha$ ), interleukin-1 beta (IL-1 $\beta$ ), inducible nitric oxide synthase (iNOS), cyclooxygenase-2 (COX-2), glutathione peroxidase (GPx), catalase (CAT), monocyte chemoattractant protein-1 (MCP-1), macrophage inflammatory protein-2 (MIP-2), KC (murine IL-8 ortho$\log$ ), transforming growth factor-betal (TGF- $\left.\beta_{1}\right)$, procollagen-1 (PC-1), alpha-smooth muscle actin $(\alpha$-SMA) and suppressor of cytokine signaling-3 (SOCS-3) were measured by Takara SYBR premix Taq quantitative PCR system (Takara Bio Inc, Shiga, Japan) and in MyiQ2 realtime PCR machine (Bio-Rad). The primer sequences and annealing temperatures used in those Q-PCR are listed in Table 1. All primers were designed by using Primer Premier 5 (Premier Biosoft, Palo Alto, CA, USA) software with specificity validation. PCR efficiency of each primer pair was tested. Parallel amplification of glyceraldehyde-3phosphate dehydrogenase (GAPDH) was used as the internal control. Relative quantification was done by using the $2^{-\Delta \Delta \mathrm{Ct}}$ method. The relative expression of the specific gene to the internal control was obtained and then expressed as a percentage of the control value in the figures. All quantitative PCR procedures including the design of primers, validation of PCR environment and quantification methods were performed according the MIQE guideline [16].

\section{Western blot analysis}

Cytosolic and nuclear protein extraction of rat liver was conducted using NE-PER protein extraction system (Pierce Biotechnology, Rockford, IL, USA) with the addition of Halt phosphatase inhibitor cocktail (Pierce). Before Western blot, protein was diluted and mixed with $2 \times$ sample buffer $(0.1 \mathrm{M}$ Tris- $\mathrm{HCl}, \mathrm{pH} \quad 6.8,20 \%$ glycerol, $4 \%$ sodium dodecyl sulfate, 0.2\% Bromophenol Blue, 5.25\% $\beta$-mercaptoethanol). The mixture was denatured at $99^{\circ} \mathrm{C}$ for $5 \mathrm{~min}$ and followed by electrophoresis in a $10 \%$ polyacrylamide gel. The protein was then transferred to an Immun-Blot ${ }^{\mathrm{TM}}$ PVDF Membrane (Bio-Rad) in a TE series transfer electrophoresis unit (Hoefer Inc., Holliston, MA, USA). The membrane was then incubated in blocking buffer (5\% non-fat milk powder in TBST, $100 \mathrm{mM}$ Tris$\mathrm{HCl}, \mathrm{pH} 7.5,0.9 \% \mathrm{NaCl}, 0.1 \%$ Tween 20 ) for $1 \mathrm{~h}$ followed by incubation with different primary antibodies in TBST overnight at $4{ }^{\circ} \mathrm{C}$ with gentle agitation. On the following day, the membrane was washed with TBST and incubated with appropriate secondary antibodies for $2 \mathrm{~h}$ at room temperature. Beta-actin was used as the internal control. After washing off the unbound antibody with TBST, the expression of the antibody-linked protein was determined by an ECL ${ }^{\mathrm{TM}}$ Western Blotting Detection Reagents (GE Healthcare). The optical density of the bands was measured and quantified by ImageJ software (National Institute of Health, MD). The ratio of the optical density of the protein product to the internal control was obtained and was expressed as a percentage of the control value in the figures. 
Table 1 Primer sequences and annealing temperatures for quantitative PCR

A. Temp. annealing temperature

\begin{tabular}{|c|c|c|c|}
\hline Target gene & Direction & Primer sequence $\left(5^{\prime}-3^{\prime}\right)$ & A. Temp. $\left({ }^{\circ} \mathrm{C}\right)$ \\
\hline \multirow[t]{2}{*}{ SREBP1c } & Forward & GGAGCCATGGATTGCACATT & 58 \\
\hline & Reverse & GCTTCCAGAGAGGAGCCCAG & \\
\hline \multirow[t]{2}{*}{ Adiponectin } & Forward & TAAGGGTGACCCAGGAGATG & 58 \\
\hline & Reverse & GGA ACATTGGGGACAGTGAC & \\
\hline \multirow[t]{2}{*}{ TNF- $\alpha$} & Forward & ATGAGCACAGAAAGCATGATC & 62 \\
\hline & Reverse & TACAGGCTTGTCACTCGAATT & \\
\hline \multirow[t]{2}{*}{ IL- $1 \beta$} & Forward & CACCTCTCAAGCAGAGCACAG & 60 \\
\hline & Reverse & GGGTTCCATGGTGAAGTCAAC & \\
\hline \multirow[t]{2}{*}{ iNOS } & Forward & CATTGGAAGTGAAGCGTTTCG & 58 \\
\hline & Reverse & CAGCTGGGCTGTACAAACCTT & \\
\hline \multirow[t]{2}{*}{$\mathrm{COX}-2$} & Forward & TGTATGCTACCATCTGGCTTCGG & 58 \\
\hline & Reverse & GTTTGGAACAGTCGCTCGTCATC & \\
\hline \multirow[t]{2}{*}{ GPx } & Forward & TCCACCGTGTATGCCTTCTCC & 58 \\
\hline & Reverse & CCTGCTGTATCTGCGCACTGGA & \\
\hline \multirow[t]{2}{*}{ CAT } & Forward & GAGGCAGTGTACTGCAAGTTCC & 58 \\
\hline & Reverse & GGGACAGTTCACAGGTATCTGC & \\
\hline \multirow[t]{2}{*}{ MCP-1 } & Forward & ACCAGCCAACTCTCACTGAAGC & 60 \\
\hline & Reverse & CAGAATTGCTTGAGGTGGTTGTG & \\
\hline \multirow[t]{2}{*}{ MIP-2 } & Forward & AGTGAACTGCGCTCTCAATG & 55 \\
\hline & Reverse & CTTTGGTTCTTCCGTTGAGG & \\
\hline \multirow[t]{2}{*}{$\mathrm{KC}$} & Forward & CTGTCAGTGCCTGCAGACCA & 56 \\
\hline & Reverse & CCAAGGGAGCTTCAGGGTCA & \\
\hline \multirow[t]{2}{*}{ IL-6 } & Forward & CCGGAGAGGAGACTTCACAG & 60 \\
\hline & Reverse & GGAAATTGGGGTAGGAAGGA & \\
\hline \multirow[t]{2}{*}{ TGF- $\beta_{1}$} & Forward & CTTCAGCTCCACAGAGAAGAACTGC & 60 \\
\hline & Reverse & CACGATCATGTTGGACAACTGCTCC & \\
\hline \multirow[t]{2}{*}{ PC-1 } & Forward & TGCCGTGACCTCAAGATGTGCC & 60 \\
\hline & Reverse & CATCCACAAGCGTGCTGTAGGTG & \\
\hline \multirow[t]{2}{*}{$\alpha$-SMA } & Forward & CTGGAGAAGAGCTACGAACTGC & 55 \\
\hline & Reverse & CTGATCCACATCTGCTGGAAGG & \\
\hline \multirow[t]{2}{*}{ SOCS-3 } & Forward & CCTCCAGCATCTTTGTCGGAAGAC & 58 \\
\hline & Reverse & TACTGGTCCAGGAACTCCCGAATG & \\
\hline \multirow[t]{2}{*}{ GAPDH } & Forward & CCTTCATTGACCTCAACTACATGGT & 55 \\
\hline & Reverse & TCATTGTCATACCAGGAAATGAGCT & \\
\hline
\end{tabular}

Enzyme-linked immunosorbent assay (ELISA) measurement

To correlate the mRNA expression with protein expression of selected target genes in the liver, ELISA measurements of TNF- $\alpha$, IL- $1 \beta$, MCP-1 and TGF- $\beta_{1}$ were performed by using corresponding ELISA development kits from PeproTech (PeproTech Inc., Rocky Hill, NJ, USA) according to user instructions.

DNA-binding activity of nuclear factor- $\kappa \mathrm{B}(\mathrm{NF}-\kappa \mathrm{B})$ and activator protein-1 (AP-1)

Determination of $\mathrm{NF}-\kappa \mathrm{B}$ and $\mathrm{AP}-1$ are the major transcription factors in the regulation of inflammation and oxidative stress. The DNA-binding activity of these factors was performed by electrophoretic mobility shift assay (EMSA) using the Gel-Shift Assay Systems from Promega (Promega, Madison, WI, USA). Briefly, the phosphorylated and purified consensus NF- $\kappa \mathrm{B}$ or AP-1 oligonucleotides (Promega) with ${ }^{32} \mathrm{P}$ labeling was mixed with $24 \mu \mathrm{g}$ of nuclear protein extract and $10 \times$ Gel-Shift Binding Buffer (200 mm Tris-HCl, pH 7.8, $1 \mathrm{~m} \mathrm{NaCl}, 50 \mathrm{~mm} \mathrm{MgCl}_{2}$, $10 \mathrm{~mm}$ EDTA and $50 \mathrm{~mm}$ dithiothreitol). The mixture was incubated at room temperature for $20 \mathrm{~min}$ prior to electrophoresis on a $4 \%$ non-denaturing polyacrylamide gel. Signals on exposed X-ray films were quantified using laser scanning densitometry. Specificity of $\mathrm{NF}-\kappa \mathrm{B}$ binding was confirmed by competition assays and the ability of a specific antibody to supershift protein-DNA complexes. 
In the competition assay, the addition of 100-fold excess of unlabeled competitor consensus oligonucleotide prevented binding. To confirm the specificity of NF- $\kappa \mathrm{B}$ or AP-1 binding, supershift experiments with p50/p60 antibody addition or c-Jun antibody addition were performed, respectively.

\section{Statistical analysis}

Data from each group were expressed as means \pm SEM. Statistical comparison between groups was done using the Kruskal-Wallis test followed by Dunn's post hoc test to detect differences in all groups. A $p<0.05$ was considered to be statistically significant (Prism 5.0, Graphpad software, Inc., San Diego, CA, USA).

\section{Results}

Since NAFLD is characterized by liver injury and fibrosis, as well as increased FFAs in the blood, we measured the effects of SAMC administration along with the NAFLD development on liver histology, serum ALT and FFAs levels. NAFLD induced cellular necrosis, inflammation and collagen accumulation surrounding the centrilobular veins of the liver (Fig. 1b, f). Co-treatment of SAMC markedly attenuated the hepatic injury, steatosis, inflammation and fibrosis without affecting the normal liver cells (Fig. 1d, h). The percentage of collagen distribution of the liver also showed a marked reduction in the amount of collagen in SAMC co-treatment rats, which supported the anti-fibrotic effects of the SAMC treatment (Fig. 1i). The NAS score of NAFLD rats was high $(5.67 \pm 0.49)$, indicating severe steatohepatitis after the induction from high-fat diet. Co-treatment with SAMC significantly reduced the NAS score to a "borderline of NASH" level (3.42 \pm 0.57 ; Fig. $1 \mathrm{j})$ [15]. Moreover, serum ALT-indicated lesser injury and FFAs induced by NAFLD were significantly down-regulated to control levels by SAMC co-treatment (Fig. 1k, 1).

Increased expression of lipogenesis marker gene (SREBP1c) was observed in the NAFLD rats, whereas the expression of lipolysis marker gene (adiponectin) was reduced, suggesting an on-going process of hepatic lipid accumulation. Addition of SAMC reversed such trend by down-regulating SREBP1c and up-regulating adiponectin (Fig. 2a, b).

To further study the effects of SAMC on hepatic fibrosis, expression change of key pro-fibrogenic mediators including TGF- $\beta_{1}, \alpha$-SMA and PC- 1 were measured by quantitative PCR or ELISA. NAFLD induced the expression of TGF- $\beta_{1}$ and $\alpha$-SMA at both transcriptional and translational levels. When SAMC was co-treated, these genes were down-regulated and reduced to levels almost comparable to their corresponding controls (Fig. 2c-e). The PC-1 mRNA expression in SAMC co-treatment group also showed significant reduction when compared with NAFLD rats (Fig. 2f).

To investigate the possible protective function of SAMC on increased oxidative stress that plays a critical role on the further development of steatohepatitis, key oxidative stress markers during NAFLD were measured. Up-regulated expression of CYP2E1 during NAFLD was counteracted by SAMC co-treatment (Fig. 3a). Administration of SAMC also restored the mRNA expression of antioxidant enzymes, CAT and GPx, which were down-regulated during NAFLD (Fig. 3b, c). Co-treatment of SAMC also reduced the formation of MDA and nitrotyrosine during NAFLD development without disturbing their basal levels (Fig. 3d, e).

Inflammation and subsequent chemoattraction of cell migration to the liver are critical for the development and progression of NAFLD [17]. We measured several inflammatory mediators and chemokines in NAFLD rats with or without SAMC co-treatment. Consistent with previous reports, NAFLD induced expressions of pro-inflammatory mediators (TNF- $\alpha$, IL- $1 \beta$, iNOS, COX-2) (Fig. 4a-f) and chemokines (MCP-1, MIP-2, KC) (Fig. 5a-d) at both mRNA and protein levels. Administration of SAMC during NAFLD development significantly attenuated the inductions of the expression levels of these inflammatory mediators when compared to the controls, with values near to control levels. As the negative regulator of the inflammatory response, both mRNA and protein expressions of SOCS3 were increased during NAFLD development. Co-treatment of SAMC also abolished the induced SOCS3 expression (Fig. 4g, h).

To study the signaling pathway involved in the pathophysiological processes of NAFLD induced by the elevation of FFA and the effects of SAMC intervention, we measured the phosphorylation status and total expression of MAPK kinases signaling pathways including p38 MAPK, JNK and MEK/ERK, which play important roles in insulin and inflammatory responses [18, 19]. Interestingly, our result showed that an increase in the phosphorylation level of p38 MAPK and JNK/c-Jun, but a decrease in the phosphorylation of MEK/ERK1/2 was observed in NAFLD rat liver tissue. This finding suggested that the MAPK kinase pathways were differentially regulated during the development of NAFLD. Co-treatment of SAMC counteracted all the effects of NAFLD induction on the phosphorylation of these kinases without influencing the total expression levels except for total p38 MAPK where it was reduced by SAMC administration (Fig. 6a-c).

As critical regulators of cellular inflammation, proliferation and apoptosis, the activity of nuclear transcription factors $\mathrm{NF}-\kappa \mathrm{B}$ and AP-1 were induced in NAFLD rats. Co-treatment of SAMC during NAFLD induction significantly reduced the 

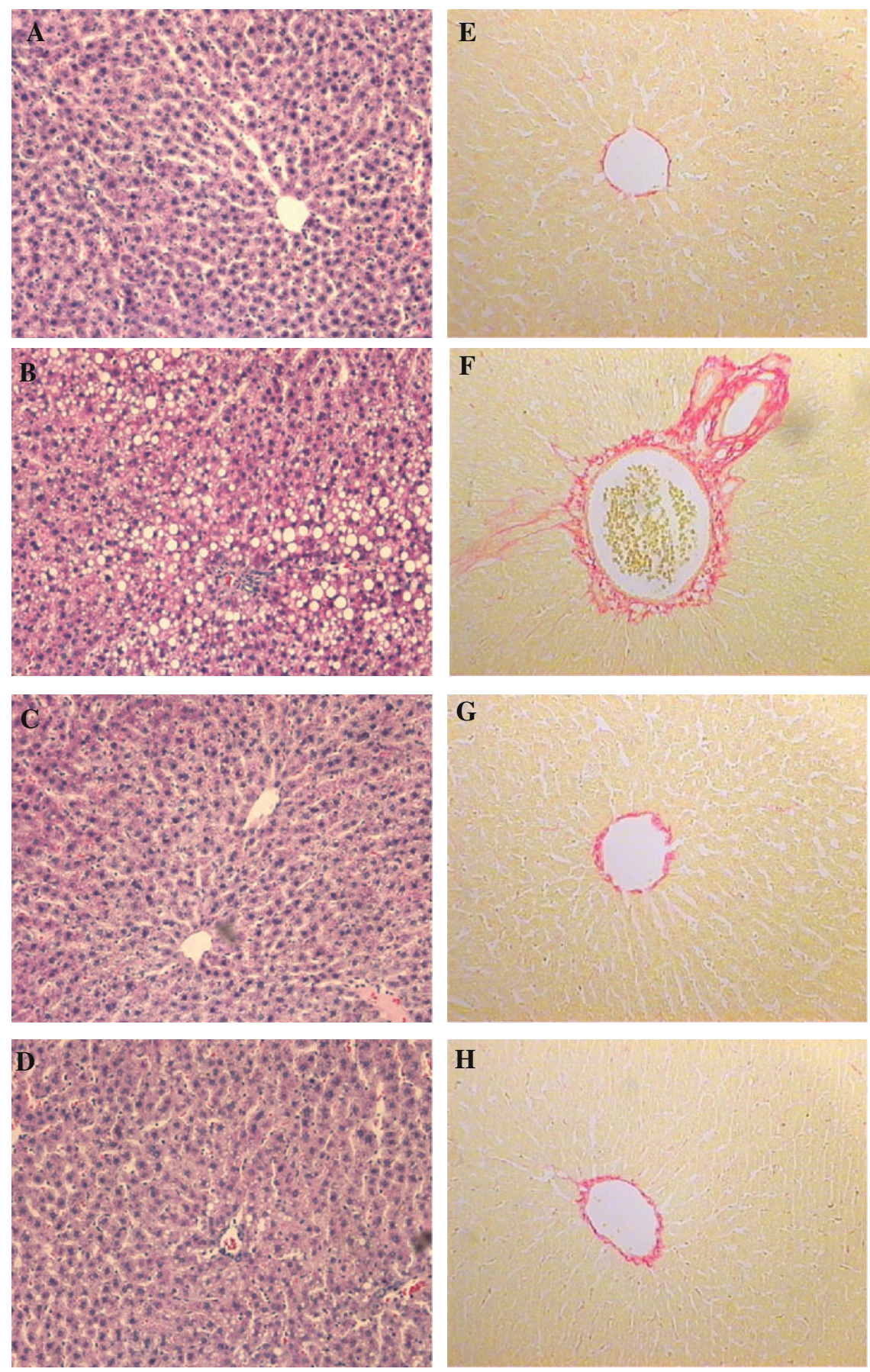
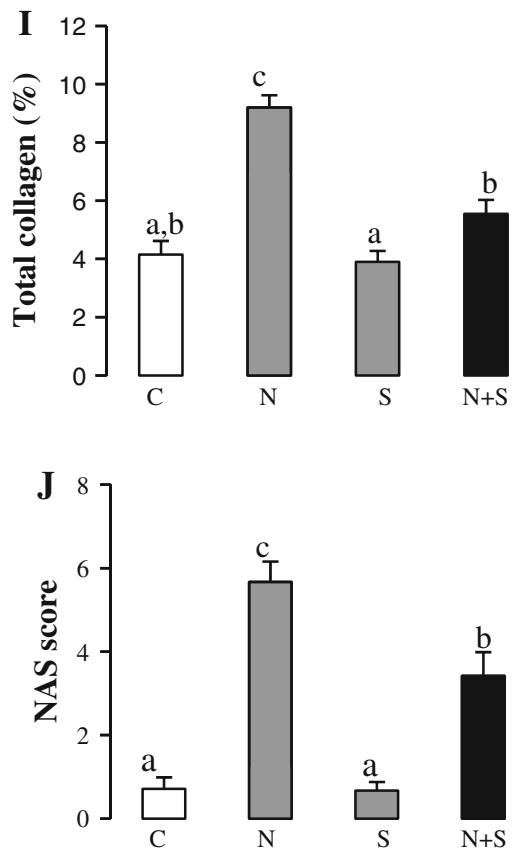

\section{$\mathbf{K}$}
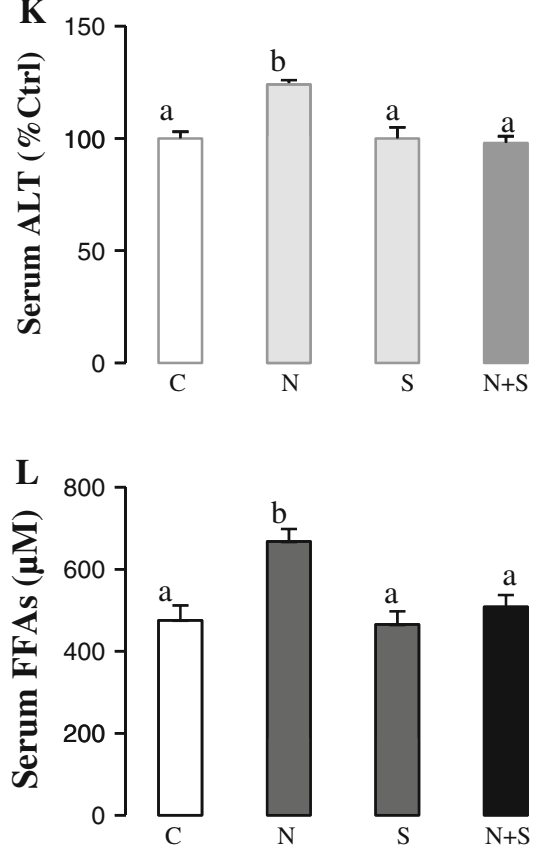

Fig. 1 Ameliorative effects of SAMC on liver injury, collagen accumulation and excessive free fatty acids. Liver H\&E staining of a control group, b NAFLD group, $\mathbf{c}$ SAMC group and $\mathbf{d}$ NAFLD+SAMC group. Liver Sirius Red staining of $\mathbf{e}$ control group, $\mathbf{f}$ NAFLD group, $\mathbf{g}$ SAMC group and $\mathbf{h}$ NAFLD+SAMC group. $\mathbf{i}$ Percentage of total collagen of liver with Sirius Red staining, $\mathbf{j}$ NAS scoring of liver H\&E staining, $\mathbf{k}$ serum ALT level and $\mathbf{l}$ serum free fatty acids (FFAs) level of each group. Magnification: $\times 200$. Data presented are expressed as Mean \pm SEM $(n=7)$ and experimental groups marked by different letters represented significant differences between groups at $p<0.05$ (KruskalWallis test followed by Dunn's post hoc test). $C$ control, $N$ NAFLD, $S$ SAMC; $N+S$ NAFLD + SAMC

phosphorylation of $\mathrm{I} \kappa \mathrm{B} \alpha$ and recovery of degraded total $\mathrm{I} \kappa \mathrm{B} \alpha$ in the cytosol (Fig. 6d). Supershift assay for NF- $\kappa \mathrm{B}$ and AP-1 were used to confirm the specificities of these assays (Fig. 6e, g). 
Fig. 2 SAMC restored lipid metabolism status and reduced fibrogenic factors induced by NAFLD. Expression levels of a SREBP1c mRNA,

b adiponectin mRNA, $\mathbf{c}$ TGF- $\beta_{1}$ mRNA, d TGF- $\beta_{1}$ protein, e $\alpha$-SMA mRNA and f PC- 1 mRNA were measured in rat liver after NAFLD development with or without co-treatment of SAMC by quantitative PCR or ELISA. Data presented are expressed as Mean \pm SEM $(n=7)$ and experimental groups marked by different letters represented significant differences between groups at $p<0.05$ (Kruskal-Wallis test followed by Dunn's post hoc test). $C$ control, $N$ NAFLD, $S$ SAMC,

$N+S$ NAFLD + SAMC
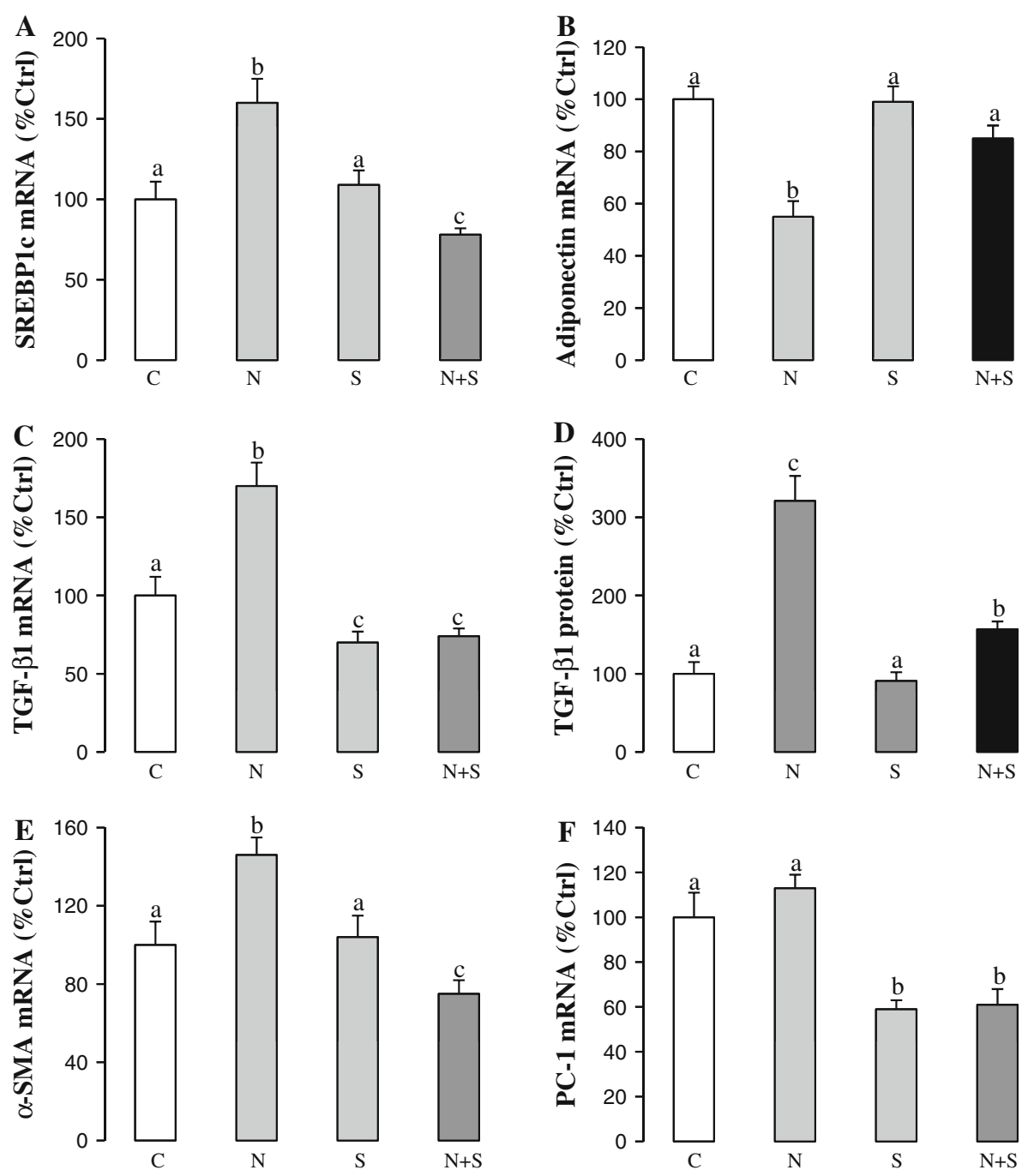

\section{Discussion}

Common animal models that mimic the initiation and progression of NAFLD such as in dietary feeding and genetic manipulation have certain disadvantages. For example, a high-fat diet model lacks obvious steatohepatitis and genetic models (e.g. leptin, agouti, SREBP1c) often show decreased body weight, cellular fibrosis and inflammation [20]. The model used in the current study prevailed over such disadvantages by showing moderate levels of cellular fibrosis, oxidative stress, necroinflammation and significant increase in body weight (Supple Fig. 1A). Considering the fat composition in our diet recipe is closer to the clinical NAFLD fat level of about $30 \%$ when compared to other high-fat diet models (45-75\%), the animal model used in the current study is better suited and is more physiological for studying the basic pathogenesis of NAFLD. Addition of SAMC effectively attenuated the pathological features of NAFLD in this model

(e.g. hepatic injury, imbalance of lipid metabolism, fibrosis, oxidative stress and inflammation) without influencing the food intake of rats (Suppl. Fig. 1B), suggesting that the protective effects of SAMC were not simply from the reduction of food intake or loss of the body weight of rats, but may be from the direct or indirect actions of SAMC.

According to the "multi-hit" hypothesis, disrupted lipid metabolism and insulin resistance is the first step toward NAFLD development. Co-treatment with SAMC not only reduced the serum FFAs level that may induce the initial pathological changes during NAFLD [21], but also significantly lowered the lipid accumulation within the hepatocytes (Fig. 1). At the molecular level, this phenomenon was proven by the restoration of the lipid metabolism-related genes SREBP1c and adiponectin (Fig. 2). The mechanism whereby excessive FFAs in the blood induce insulin resistance is partly through the mediation of protein kinase $\mathrm{C}$, resulting in impaired function of insulin receptor substrate-1 (IRS-1), which further 
Fig. 3 Ameliorating effects of SAMC on NAFLD-induced oxidative stress. Expression of a cytochrome $\mathrm{P} 450$ 2E1 (CYP2E1) protein, b CAT mRNA, c GPx mRNA, d MDA formation and e nitrotyrosine formation were measured in rat liver after NAFLD development with or without co-treatment of SAMC by quantitative PCR or Western blot. Data presented are expressed as Mean \pm SEM $(n=7)$ and experimental groups marked by different letters represented significant differences between groups at $p<0.05$ (Kruskal-Wallis test followed by Dunn's post hoc test). $C$ control, $N$ NAFLD, $S$ SAMC, $N+S$ NAFLD + SAMC
A
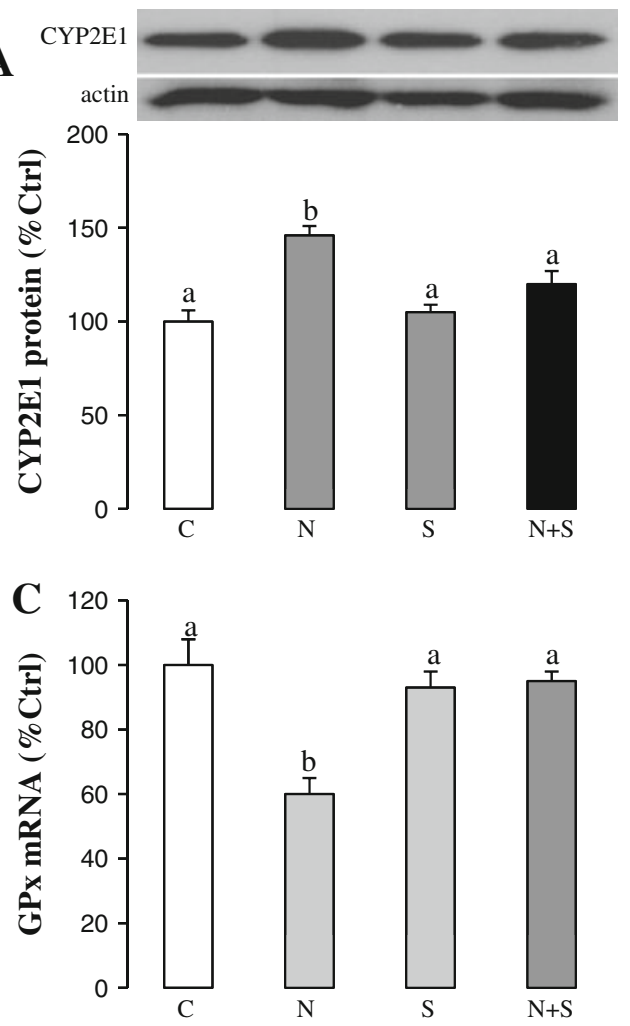
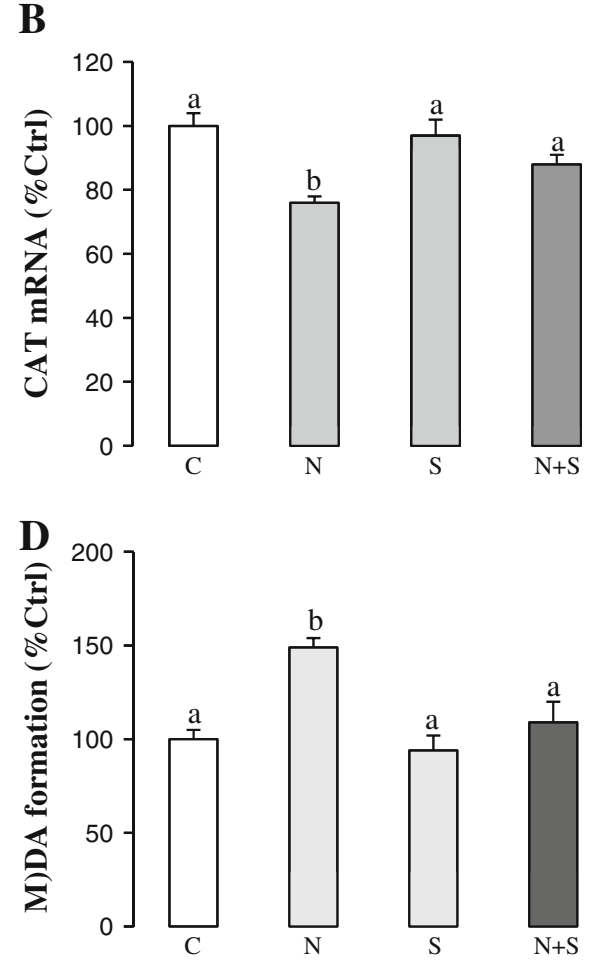

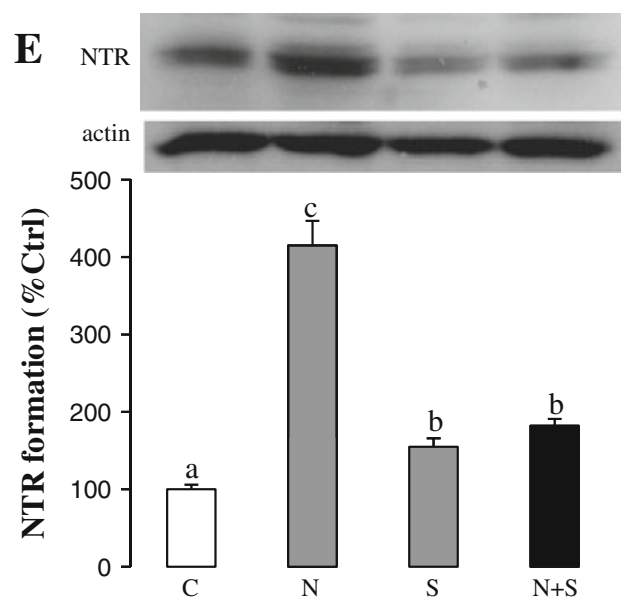

activates JNK and SOCS3, contributing to insulin resistance [22-24]. In the current study, induced phosphorylation of JNK and up-regulated level of SOCS3 were reversed by the administration of SAMC, demonstrating the effectiveness of SAMC to suppress the process of FFAs-induced lipid imbalance, which might be one of the causal factors of insulin resistance (Figs. 3, 6).

In addition to the induction of hyperinsulinemia, excessive FFAs can also trigger the release of ROS and proinflammatory mediators from impaired liver cell organelles, thus contributing to the subsequent "hits" in the progression of NAFLD [25]. NAFLD development in our current model induced the expression of CYP2E1, which mediated the inhibition of antioxidant enzymes GPx and CAT, as well as the formation of lipid peroxidation end product (MDA) and NO metabolism end product (nitrotyrosine), leading to increased oxidative stress within the cell. Furthermore, increased inflammatory cytokines and chemokines, which are partly induced through the activation of NF- $\kappa \mathrm{B}$, further aggravated NAFLD by enhancing apoptosis and necrosis of the liver cells [26]. Since increased iNOS is an inducer of NO production, which takes part in cellular oxidative stress, there is also a positive feedback loop between oxidative stress and inflammation during the NAFLD development. In the current study, administration of SAMC reversed all these stimulatory processes and inhibitory effects of 
Fig. 4 Anti-inflammation properties of SAMC during NAFLD development.

Expression of a TNF- $\alpha$ mRNA, b TNF- $\alpha$ protein, $\mathbf{c}$ IL- $1 \beta$ mRNA, d IL- $1 \beta$ protein, e iNOS mRNA, f COX-2 mRNA, g SOCS3 mRNA and $\mathbf{h}$ SOCS3 protein were measured in rat liver after NAFLD development with or without co-treatment of SAMC by quantitative PCR or ELISA/Western blot. Data presented are expressed as Mean $\pm \operatorname{SEM}(n=7)$ and experimental groups marked by different letters represented significant differences between groups at $p<0.05$ (KruskalWallis test followed by Dunn's post hoc test). $C$ control, $N$ NAFLD, $S$ SAMC,

$N+S$ NAFLD + SAMC
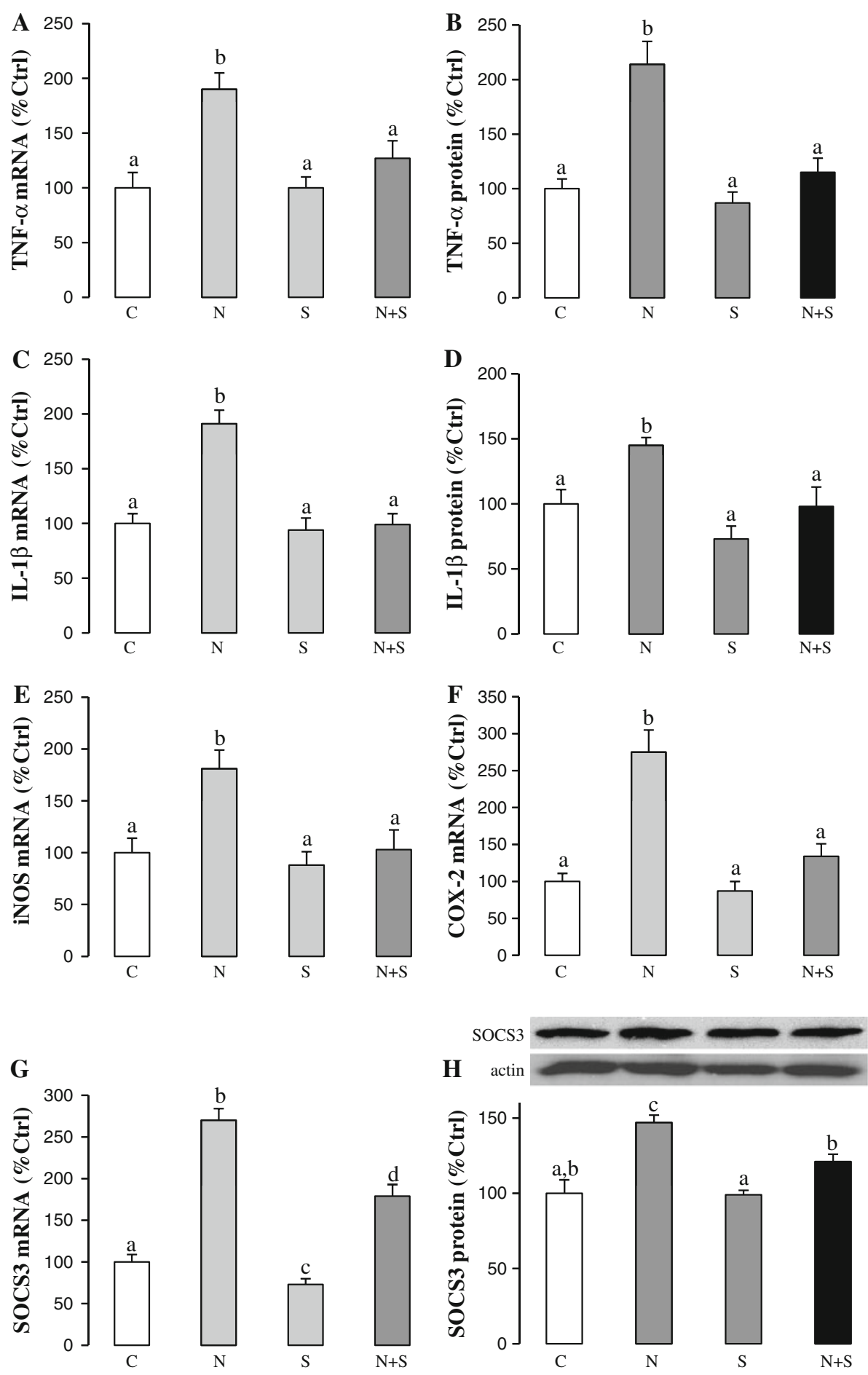

NAFLD on oxidative stress and inflammatory markers, which further demonstrated SAMC's potent protective capability against NAFLD.

Molecules that initiate hepatic fibrosis (e.g. TGF- $\beta_{1}$ and $\alpha$-SMA) may also be activated by excessive FFAs through lipid peroxidation or cytokine production [26, 27]. In addition, activated hepatic Kupffer cells, the direct source of pro-inflammatory cytokine production, may in turn activate hepatic stellate cells (HSCs) to synthesize collagen, initiating the process of liver remodeling in the form of fibrosis and cirrhosis [28]. SAMC treatment not only attenuated the gene expression levels of TGF- $\beta_{1}$ and $\alpha$-SMA, but also reduced collagen accumulation around the centrilobular veins. 
Fig. 5 Co-treatment of SAMC reduced NAFLD-induced chemokine expression. Expression level of a MCP-1 mRNA, b MCP-1 protein, c MIP-2 mRNA and d KC mRNA were measured in rat liver after NAFLD development with or without co-treatment of SAMC by quantitative PCR or ELISA. Data presented are expressed as Mean \pm SEM $(n=7)$, and experimental groups marked by different letters represented significant differences between groups at $p<0.05$ (Kruskal-Wallis test followed by Dunn's post hoc test). $C$ control, $N$ NAFLD, $S$ SAMC, $N+S$ NAFLD + SAMC
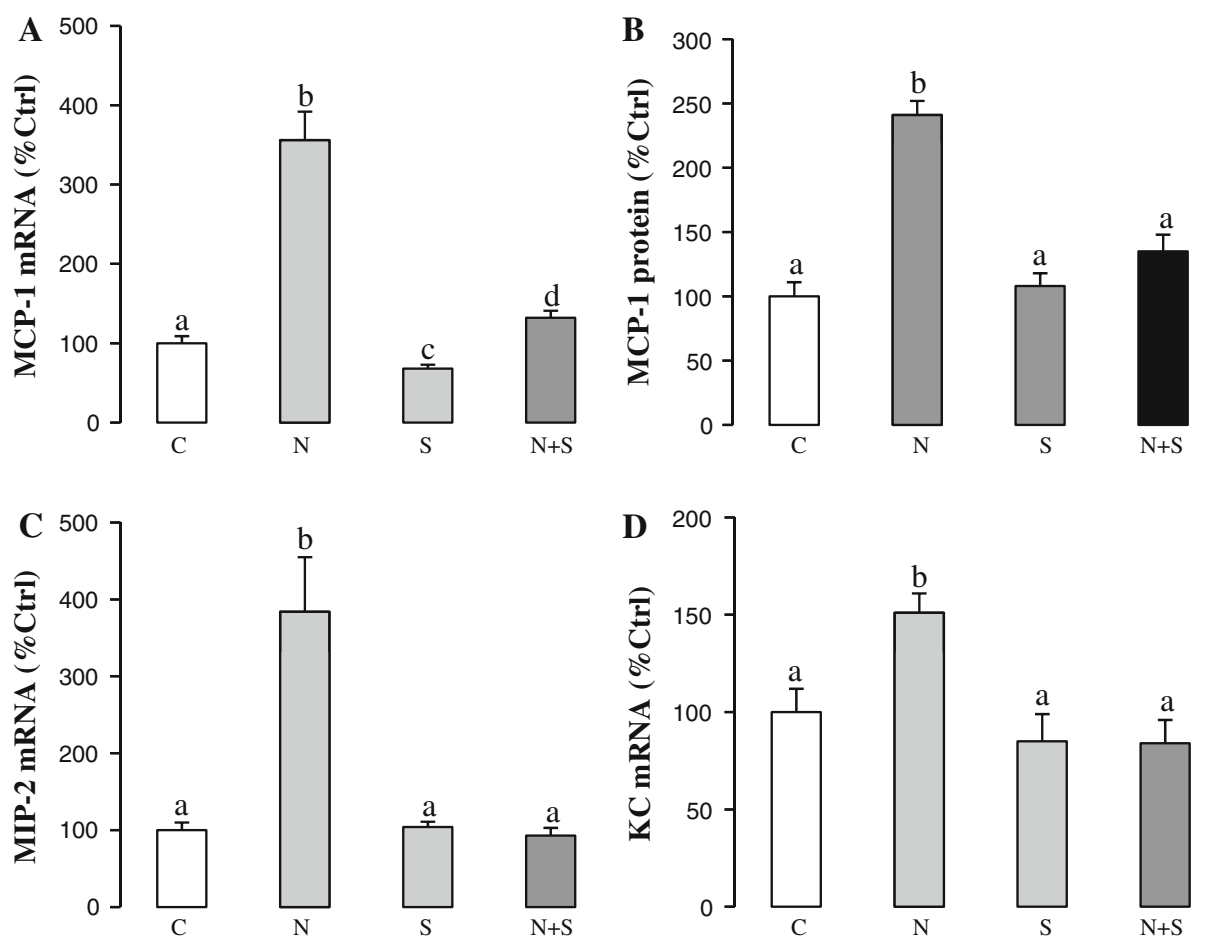

To further elaborate the molecular signaling pathways that link excessive FFAs and pathological events in NAFLD influenced by SAMC intervention, we evaluated the activation of MAPK kinases by phosphor-specific antibodies. It has recently been shown that the blockage of $\mathrm{p} 38$ MAPK in endothelial cells can prevent FFAs-induced insulin resistance through promoting the expression of PTEN gene or Akt phosphorylation [29]. Other reports also pointed out that the blockage of $\mathrm{p} 38$ MAPK accomplishes its anti-insulin resistance effect by decreasing both phosphorylation and basal expression of IRS1/2 genes [30, 31]. Here, we showed that the phosphorylation of p38 MAPK was significantly increased in NAFLD rat but decreased after the co-treatment of SAMC, suggesting the involvement of this kinase during NAFLD development and SAMC intervention. In addition, the role of JNK/c-Jun pathway in FFAs-induced insulin resistance is well studied. In the liver, JNK activity is increased in animal with insulin resistance. JNK1 knockout mice are resistance to high-fatdiet-induced insulin resistance [32]. Moreover, activation of JNK is known to promote inflammatory response and apoptosis in animal steatohepatitis model [33, 34]. Taken together, in this study, inhibition of the JNK/c-Jun phosphorylation by SAMC treatment not only attenuated the FFAs-induced insulin resistance, but also contributed to the reduction of necroinflammation during NAFLD. For the decrease in the phosphorylations of MEK1/2 and ERK1/2, our findings were consistent with a previous report conducted in a methionine-choline deficient (MCD) mice model [35]. The inhibition of MEK1/2/ERK1/2 and subsequent increased activity of transcription of AP-1 are responsible for hepatocyte sensitization to oxidative stress for cell death induction $[35,36]$. Thus, the restoration of MEK1/2/ERK1/2 and inhibition of AP-1 activity by SAMC seem to be one of the important effects of SAMC when exerting its hepato-protective function during NAFLD. It is worth noting that when compared to the level of control group, SAMC treatment alone and SAMC + NAFLD co-treatment significantly increased the phosphorylation status of MEK1/2 and ERK1/2 (Fig. 6b). Since activation of MEK/ERK pathway is essential for the mediation of cell proliferation [37], the over phosphorylation of these kinases in the current study may imply the promotion of liver regeneration during NAFLD progression. Increased expression of liver regeneration marker gene, IL-6, further lends support to this hypothesis (Suppl. Fig. 2).

The activation of NF- $\kappa \mathrm{B}$ during NAFLD relies mainly on the degradation of inhibitor of NF- $\kappa \mathrm{B}$, which is $\mathrm{I} \kappa \mathrm{B}$. ROS and pro-inflammatory cytokines initiate the degradation of $\mathrm{I} \kappa \mathrm{B}$ [38]. Since NF- $\kappa \mathrm{B}$ is the master regulator of molecules that take part in cellular proliferation, inflammation and apoptosis, then the inhibition of NF- $\kappa$ B by SAMC during NAFLD might be a critical step for the prevention of cascading inflammatory response and oxidative stress injury in the liver [5]. In this study, we clearly demonstrated that the inhibition of NF- $\kappa$ B by SAMC was through the recovery of cytosolic $\mathrm{I} \kappa \mathrm{B}$ expression (Fig. 6D).

In conclusion, we have, for the first time, reported the hepatoprotective effects of garlic-derived SAMC in a NAFLD rat model in vivo. Such protective effects are 
Fig. 6 The effects of SAMC on signaling molecules and transcription factors, which mediate NAFLD-induced insulin resistance and liver injury. Representative results of the phosphorylation status and total expression of a p38 MAPK, b MEK1/2-ERK1/2 and $\mathbf{c}$ JNK-c-Jun pathways were measured by Western blot. Activities of $\mathbf{d}$ NF- $\kappa \mathrm{B}$ and f AP-1 were measured in rat liver nucleic protein by ${ }^{32} \mathrm{P}$-labeled gel-shift assay. Specificity of NF- $\kappa \mathrm{B}(\mathbf{e})$ and AP-1 (g) were tested by incubating p50/p65 and c-Jun antibodies with nucleic protein, respectively. Numerical values represent the mean ratio and SEM of the optical density of phosphorylated form divided by total form of protein, or the optical density of radioactive bands $(n=7)$. Control group is set as 1.0. $C$ control, $N$ NAFLD, $S$ SAMC, $N+S$ NAFLD+SAMC. Asterisk represents $p<0.05$ versus control group, while Hash represents $p<0.05$ versus NAFLD group

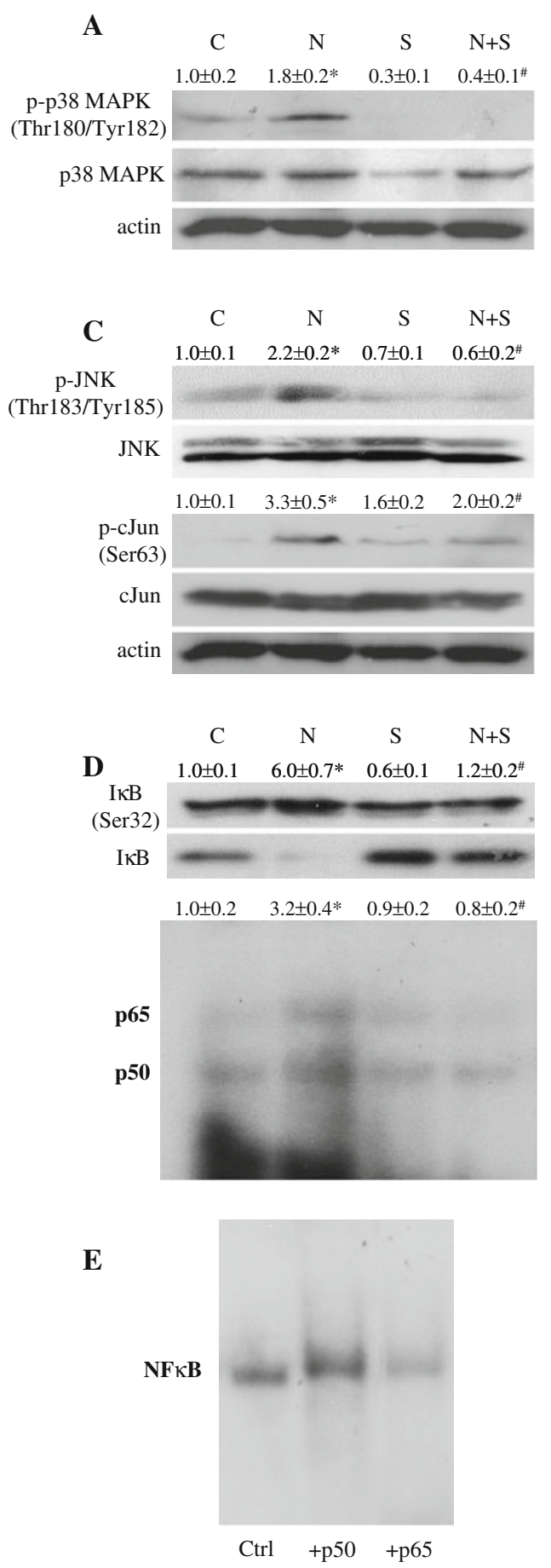

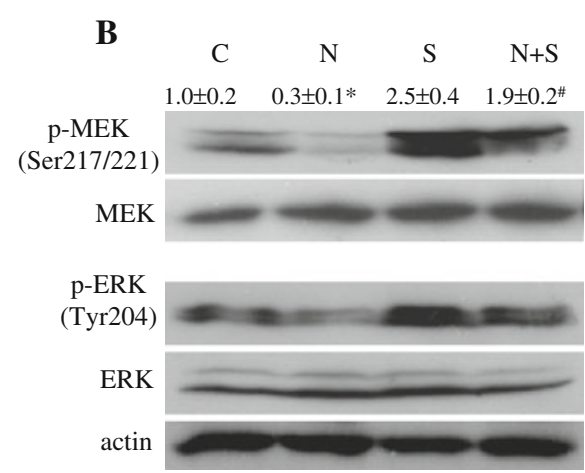
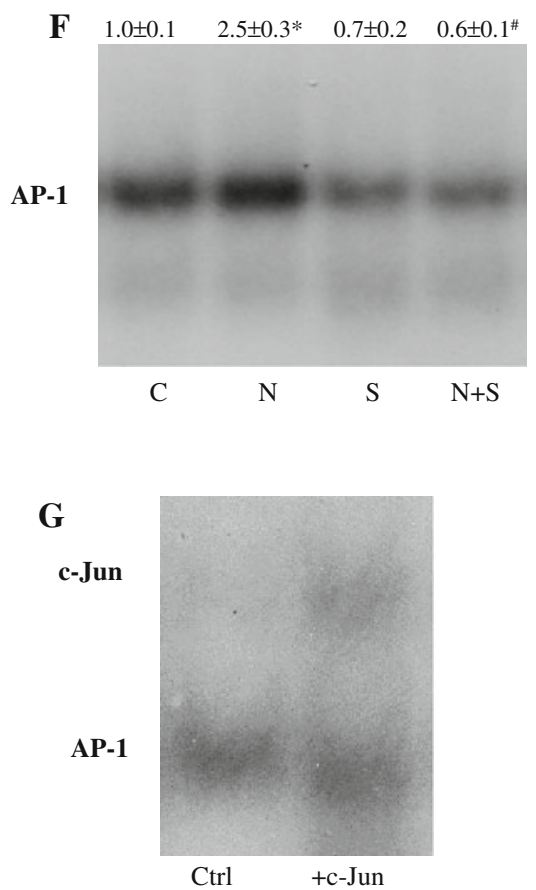

partly explained through the reduction on excessive FFAsdependent pathways, fibrosis, oxidative stress, inflammation and diminished in the nuclear transcription factors (NF- $\kappa \mathrm{B}$ and AP-1) activity during NAFLD development. MAPKs also mediated the attenuation of NAFLD pathological events by SAMC. However, the mediators between SAMC and FFAs has still need to be experimentally identified and further investigated. Expressional changes of FFAs, lipid metabolism genes and MAPKs indirectly indicated the possible improvement of insulin resistance from SAMC co-treatment. However, direct evidence from insulin tolerance test and glucose tolerance test on rats are essential to validate the possible beneficial effects of SAMC on insulin resistance. In addition, although the administration method used in the current study is intraperitoneal injection, previous study in human showed that oral administration of SAMC demonstrated its beneficial effect [39]. Actually, the dose of SAMC (200 mg/kg) used 
is not realistic for human consumption of aged garlic. However, a study in animal model within a relatively short period required a higher dose of SAMC in order to demonstrate the possible beneficial effects of SAMC. For human consumption, a lower dose with long-term consumption of aged garlic may provide similar protective effects against fatty liver disease [39]. Since garlic is a common food supplement around the world, we believe that garlic or its derivatives could be considered as one of the preventive measures in the treatment strategy of NAFLD.

Acknowledgments The authors would like to thank Ms. Carman Leung for her technical help in this project. This study is supported by Small Project Funding, University Research Committee, The University of Hong Kong and General Research Fund, University Grant Council, Hong Kong SAR.

\section{Conflict of interest None.}

Open Access This article is distributed under the terms of the Creative Commons Attribution License which permits any use, distribution, and reproduction in any medium, provided the original author(s) and the source are credited.

\section{References}

1. Falck-Ytter Y, Younossi ZM, Marchesini G, McCullough AJ (2001) Clinical features and natural history of nonalcoholic steatosis syndromes. Semin Liver Dis 21:17-26

2. Loguercio C, De Simone T, D'Auria MV, de Sio I, Federico A, Tuccillo C, Abbatecola AM, Del Vecchio Blanco C, Agostinacchio E, Benedetti A, Svegliati-Baroni G, Budillon G, Cimino L, Chiaramonte M, Saltarelli P, Fraioli F, Fargion S, Fracanzani AL, Floreani A, Blasone L, Grieco A, Miele L, Rappaccini G, Gasbarrini G, Loria P, Carulli N, Marchesini G, Bianchi G, Matarazzo $\mathrm{M}$, Mecenate $\mathrm{F}$, Persico $\mathrm{M}$, De Marino $\mathrm{F}$, Portincasa $\mathrm{P}$, Palmieri V, Palasciano G, Spadaro A, Ajello A, Smedile A, Bugianesi E, Visconti M, Salvio A, Varriale M, Vecchione R, Terracciano LM, Guido M (2004) Non-alcoholic fatty liver disease: a multicentre clinical study by the Italian Association for the Study of the Liver. Digest Liver Dis 36:398-405

3. Bataller R, Brenner DA (2005) Liver fibrosis. J Clin Invest 115:209-218. doi:10.1172/jci24282

4. Polyzos SA, Kountouras J, Zavos C (2009) Nonalcoholic fatty liver disease: the pathogenetic roles of insulin resistance and adipocytokines. Curr Mol Med 9:299-314

5. Ban JO, Yuk DY, Woo KS, Kim TM, Lee US, Jeong HS, Kim DJ, Chung YB, Hwang BY, Oh KW, Hong JT (2007) Inhibition of cell growth and induction of apoptosis via inactivation of NF-kappaB by a sulfurcompound isolated from garlic in human colon cancer cells. J Pharmacol Sci 104:374-383

6. Lee Y (2008) Induction of apoptosis by S-allylmercapto-L-cysteine, a biotransformed garlic derivative, on a human gastric cancer cell line. Int J Mol Med 21:765-770

7. Xiao D, Pinto JT, Soh JW, Deguchi A, Gundersen GG, Palazzo AF, Yoon JT, Shirin H, Weinstein IB (2003) Induction of apoptosis by the garlic-derived compound S-allylmercaptocysteine (SAMC) is associated with microtubule depolymerization and c-Jun NH(2)-terminal kinase 1 activation. Cancer Res 63: 6825-6837

8. Pedraza-Chaverri J, Barrera D, Maldonado PD, Chirino YI, Macias-Ruvalcaba NA, Medina-Campos ON, Castro L, Salcedo MI, Hernandez-Pando R (2004) S-allylmercaptocysteine scavenges hydroxyl radical and singlet oxygen in vitro and attenuates gentamicin-induced oxidative and nitrosative stress and renal damage in vivo. BMC Clin Pharmacol 4:5. doi:10.1186/14726904-4-5

9. Sumioka I, Matsura T, Yamada K (2001) Therapeutic effect of S-allylmercaptocysteine on acetaminophen-induced liver injury in mice. Eur J Pharmacol 433:177-185

10. Nakagawat S, Kasuga S, Matsuura H (1989) Prevention of liver damage by aged garlic extract and its components in mice. Phytother Res 3:50-53. doi:10.1002/ptr.2650030203

11. XIao J, Liong EC, Ling MT, Ching YP, Fung ML, Tipoe GL (2011) S-allylmercaptocysteine reduces carbon tetrachloride induced hepatic oxidative stress and necroinflammmation via nuclear factor kappa B-dependent pathways in mice. Eur J Nutr. doi:10.1007/s00394-011-0217-0

12. Tipoe GL, Ho CT, Liong EC, Leung TM, Lau TY, Fung ML, Nanji AA (2009) Voluntary oral feeding of rats not requiring a very high fat diet is a clinically relevant animal model of non-alcoholic fatty liver disease (NAFLD). Histol Histopathol 24:1161-1169

13. Tipoe GL, Liong EC, Leung TM, Nanji AA (2008) A voluntary oral-feeding rat model for pathological alcoholic liver injury. Methods Mol Biol 447:11-31. doi:10.1007/978-1-59745-242-7_2

14. Sumioka I, Matsura T, Kasuga S, Itakura Y, Yamada K (1998) Mechanisms of protection by S-allylmercaptocysteine against acetaminophen-induced liver injury in mice. Jpn J Pharmacol 78:199-207

15. Kleiner DE, Brunt EM, Van Natta M, Behling C, Contos MJ, Cummings OW, Ferrell LD, Liu YC, Torbenson MS, UnalpArida A, Yeh M, McCullough AJ, Sanyal AJ, Nonalcoholic Steatohepatitis Clinical Research Network (2005) Design and validation of a histological scoring system for nonalcoholic fatty liver disease. Hepatology 41:1313-1321

16. Bustin SA, Benes V, Garson JA, Hellemans J, Huggett J, Kubista M, Mueller R, Nolan T, Pfaffl MW, Shipley GL, Vandesompele J, Wittwer CT (2009) The MIQE guidelines: minimum information for publication of quantitative real-time PCR experiments. Clin Chem 55:611-622. doi:10.1373/clinchem.2008.112797

17. Jiang J, Torok N (2008) Nonalcoholic steatohepatitis and the metabolic syndrome. Metab Syndr Relat Disord 6:1-7. doi: 10.1089/met.2007.0026

18. Mussig K, Haring HU (2010) Insulin signal transduction in normal cells and its role in carcinogenesis. Exp Clin Endocrinol Diabetes 118:356-359. doi:10.1055/s-0029-1243603

19. Melo AM, Bittencourt P, Nakutis FS, Silva AP, Cursino J, Santos GA, Ashino NG, Velloso LA, Torsoni AS, Torsoni MA (2011) Solidago chilensis Meyen hydroalcoholic extract reduces JNK/ IkappaB pathway activation and ameliorates insulin resistance in diet-induced obesity mice. Exp Biol Med (Maywood). doi: 10.1258/ebm.2011.011105

20. Schattenberg JM, Galle PR (2010) Animal models of nonalcoholic steatohepatitis: of mice and man. Digest Dis 28: 247-254

21. Lam TK, Yoshii H, Haber CA, Bogdanovic E, Lam L, Fantus IG, Giacca A (2002) Free fatty acid-induced hepatic insulin resistance: a potential role for protein kinase C-delta. Am J Physiol Endocrinol Metab 283:E682-E691. doi:10.1152/ajpendo.00038. 2002

22. Shulman GI (2000) Cellular mechanisms of insulin resistance. J Clin Invest 106:171-176. doi:10.1172/jci10583

23. Nguyen MT, Satoh H, Favelyukis S, Babendure JL, Imamura T, Sbodio JI, Zalevsky J, Dahiyat BI, Chi NW, Olefsky JM (2005) 
JNK and tumor necrosis factor-alpha mediate free fatty acidinduced insulin resistance in 3T3-L1 adipocytes. J Biol Chem 280:35361-35371. doi:10.1074/jbc.M504611200

24. Ghanim H, Aljada A, Daoud N, Deopurkar R, Chaudhuri A, Dandona P (2007) Role of inflammatory mediators in the suppression of insulin receptor phosphorylation in circulating mononuclear cells of obese subjects. Diabetologia 50:278-285. doi:10.1007/s00125-006-0508-9

25. Bastard JP, Maachi M, Lagathu C, Kim MJ, Caron M, Vidal H, Capeau J, Feve B (2006) Recent advances in the relationship between obesity, inflammation, and insulin resistance. Eur Cytokine Netw 17:4-12

26. Malaguarnera M, Di Rosa M, Nicoletti F, Malaguarnera L (2009) Molecular mechanisms involved in NAFLD progression. J Mol Med 87:679-695. doi:10.1007/s00109-009-0464-1

27. Xu ZJ, Fan JG, Ding XD, Qiao L, Wang GL (2010) Characterization of high-fat, diet-induced, non-alcoholic steatohepatitis with fibrosis in rats. Dig Dis Sci 55:931-940. doi:10.1007/ s10620-009-0815-3

28. Leclercq IA, Da Silva Morais A, Schroyen B, Van Hul N, Geerts A (2007) Insulin resistance in hepatocytes and sinusoidal liver cells: mechanisms and consequences. J Hepatol 47:142-156. doi: 10.1016/j.jhep.2007.04.002

29. Wang XL, Zhang L, Youker K, Zhang MX, Wang J, LeMaire SA, Coselli JS, Shen YH (2006) Free fatty acids inhibit insulin signaling-stimulated endothelial nitric oxide synthase activation through upregulating PTEN or inhibiting Akt kinase. Diabetes 55:2301-2310. doi:10.2337/db05-1574

30. Fujishiro M, Gotoh Y, Katagiri H, Sakoda H, Ogihara T, Anai M, Onishi Y, Ono H, Abe M, Shojima N, Fukushima Y, Kikuchi M, Oka Y, Asano T (2003) Three mitogen-activated protein kinases inhibit insulin signaling by different mechanisms in 3T3-L1 adipocytes. Mol Endocrinol 17:487-497. doi:10.1210/me.20020131

31. Liu HY, Collins QF, Xiong Y, Moukdar F, Lupo EG Jr, Liu Z, Cao W (2007) Prolonged treatment of primary hepatocytes with oleate induces insulin resistance through p38 mitogen-activated protein kinase. J Biol Chem 282:14205-14212. doi:10.1074/ jbc.M609701200

32. Hirosumi J, Tuncman G, Chang L, Gorgun CZ, Uysal KT, Maeda K, Karin M, Hotamisligil GS (2002) A central role for JNK in obesity and insulin resistance. Nature 420:333-336. doi:10.1038/ nature 01137

33. Schattenberg JM, Singh R, Wang Y, Lefkowitch JH, Rigoli RM, Scherer PE, Czaja MJ (2006) JNK1 but not JNK2 promotes the development of steatohepatitis in mice. Hepatology 43:163-172. doi:10.1002/hep.20999

34. Svegliati-Baroni G, Candelaresi C, Saccomanno S, Ferretti G, Bachetti T, Marzioni M, De Minicis S, Nobili L, Salzano R, Omenetti A, Pacetti D, Sigmund S, Benedetti A, Casini A (2006) A model of insulin resistance and nonalcoholic steatohepatitis in rats: role of peroxisome proliferator-activated receptor-alpha and n-3 polyunsaturated fatty acid treatment on liver injury. Am J Pathol 169:846-860

35. Wang Z, Yao T, Song Z (2010) Extracellular signal-regulated kinases $1 / 2$ suppression aggravates transforming growth factorbeta1 hepatotoxicity: a potential mechanism for liver injury in methionine-choline deficient-diet-fed mice. Exp Biol Med (Maywood) 235:1347-1355. doi:10.1258/ebm.2010.010160

36. Czaja MJ, Liu H, Wang Y (2003) Oxidant-induced hepatocyte injury from menadione is regulated by ERK and AP-1 signaling. Hepatology 37:1405-1413. doi:10.1053/jhep.2003.50233

37. Mebratu Y, Tesfaigzi Y (2009) How ERK1/2 activation controls cell proliferation and cell death: Is subcellular localization the answer? Cell Cycle 8:1168-1175

38. Hayden MS, Ghosh S (2004) Signaling to NF-kappaB. Genes Dev 18:2195-2224. doi:10.1101/gad.1228704

39. Tanaka S, Haruma K, Yoshihara M, Kajiyama G, Kira K, Amagase H, Chayama K (2006) Aged garlic extract has potential suppressive effect on colorectal adenomas in humans. J Nutr $136: 821 \mathrm{~S}-826 \mathrm{~S}$ 